\section{Obesity and Smoking Habits}

SIR,-I have read with great interest the article by Dr. T. Khosia and Professor C. R. Lowe (2 October, p. 10) on smoking and obesity.

Our results at the Institute of Directors Medical Centre (Table) do not show the same relationship. There is no convincing difference between any of the smoking classes. The figures have not been broken down into age groups, but we have previously shown that in our population age has little effect on the number of smokers and the amount they smoke. ${ }^{1}$ There is a tendency for absolute weight to increase with age, ${ }^{2}$ but this does not seem to be true for relative weight, except perhaps for the over 60 's. ${ }^{3}$

\begin{tabular}{|c|c|c|c|c|c|}
\hline & $\begin{array}{c}\text { Fewer } \\
\text { Cigarettes }\end{array}$ & $\begin{array}{l}\text { Given up } \\
\text { Cigarettes }\end{array}$ & $\begin{array}{c}1-19 \\
\text { Cigarettes a Day }\end{array}$ & $\begin{array}{c}20 \text { or more } \\
\text { Cigarettes a Day }\end{array}$ & Total \\
\hline Number $\quad .$. & 677 & 388 & 424 & 511 & 2,000 \\
\hline $\begin{array}{c}\% \text { more than } 10 \% \text { under- } \\
\text { weight }\end{array}$ & 7 & 9 & 14 & 13 & 11 \\
\hline$\%$ Average weight. & 65 & 61 & 60 & 57 & 61 \\
\hline$\% 10-19 \%$ Overweight & 18 & 20 & 18 & 21 & 19 \\
\hline$\% 20 \%$ or more Overweight & 10 & 10 & 8 & 9 & 9 \\
\hline
\end{tabular}

Average weight for the patients age and height calculated from the tables of the Metropolitan Insurance Company of New York.

In view of the large numbers in both series it is not likely that these differences in trends are due to chance. The most obvious difference between the two series is one of social class, our patients being almost totally from class I or II, whereas the South Wales series is presumably almost entirely social classes IV and V.

Nicotine is known to raise the blood sugar, and it may be that this tends to lead to a lower intake of carbohydrate and hence lower weight as found by Dr. Khosla and Professor Lowe. We have found an association between heavy smoking and heavy drinking; overeating may also be part of a syndrome of general overindulgence. The increased financial opportunities for this sort of be-

haviour in our patients may account for the lack of difference in relative weight between our non-smokers and heavy smokers. Those who exhibit moderation in non-smoking (1-19/day) have indeed got the lowest incidence of overweight-in agreement with Dr. Khosla and Professor Lowe.

There is general agreement that stopping smoking usually leads to weight gain. In our population we have found that this is by no means a necessity. Of 222 men who had given up smoking at follow-up a year or more after their first visit $50 \%$ had the same weight ( $\pm 5 \mathrm{lb}), 28 \%$ had gained weight, but $22 \%$ had lost weight. This does not agree with weight difference between smokers and non-smokers found by Dr. Khosla and Professor Lowe.

In future studies it would be of great interest to see if there is a true difference in the relationship between smoking and weight according to social class.-I am, etc.,

\section{G. Pincherle}

Institute of Directors Medical Centre,

London N.1

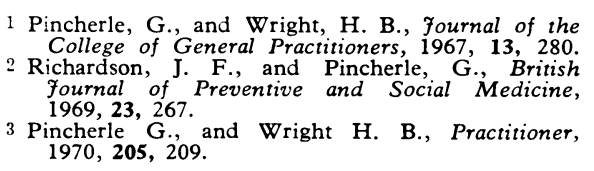

\title{
sactions
} to the M.C.V. particularly when there are striking variations in cell size and shape.

(3) Dr. Rose states "automatic apparatus is churning out normal M.C.H.C. to the accompaniment of hypochromic films" without any reference to the patients from whom these films were obtained. If these patients were hypochromic, then the machine is deceiving us, not the M.C.H.C.

As a haematologist and as I have pointed out in my book ${ }^{1}$ I believe (contrary to $\mathrm{Dr}$. Rose's view) that information of immense value (sometimes even a diagnosis) can be extracted by an experienced worker from a well prepared blood film. Even with the latest machine, the Hemalog, a blood film is invaluable in many circumstances.-I am, etc., Department of Clinical Pathology,

F. NOUR-ELDIN Shenley Hospital Nour-Eldin, F., Haematology, Rudimental,
Practical and Clinical, London, Butterworths,
1971, in press.

Cholangiogram Cannula-introducing Forceps

\section{Intravenous Practolol}

SIR,-Continuous intravenous infusion of practolol was used in the treatment of lignocaine-resistant ventricular dysrhythmia which followed ventricular fibrillation in three patients. Before starting treatment the systemic arterial pressure recordings in the three patients were $70 \mathrm{~mm} \mathrm{Hg}, 95 \mathrm{~mm} \mathrm{Hg}$, and $80 \mathrm{~mm} \mathrm{Hg}$ respectively. All three patients received intermittent positive pressure ventilation to combat pulmonary oedema. In the first case the infusion rate was $30 \mathrm{mg}$ an hour, amounting to $720 \mathrm{mg}$ a day; the second patient required an infusion rate of $25 \mathrm{mg}$ an hour, and the third patient received $1,050 \mathrm{mg}$ of practolol over 50 hours. In all cases the intravenous infusion was subsequently discontinued and practolol was given orally.

Continuous infusion studies have been carried out using oxprenolol in the treatment of dysrhythmia after cardiac infarction. ${ }^{1}$ In $59 \%$ of cases significant hypotension was reported. Despite the relatively high dose of practolol infusion we used, the systemic blood pressure showed no fall. In all our cases, after the dysrhythmia was controlled by the administration of practolol, the blood pressure started rising, the urinary output improved, and the heart failure was brought under control. Sinus bradycardia has been reported to occur after direct current shock in patients receiving the beta-blocking agent propranolol. ${ }^{2}$ Two of our patients experienced a similar effect after direct current shock, but sinus rhythm was restored after a few seconds of external cardiac massage, and on neither occasion did we have to use atropine.

We confirm Jewitt's reports ${ }^{34}$ on the effectiveness of practolol in the treatment of lignocaine-resistant ventricular dysrhythmia, as well as its less adverse haemodynamic effect when compared with other betablocking agents given intravenously.

We thank Dr. W. G. A. Swan and Dr. P. Szekely, consultant cardiologists, Dr. C. Strang, consultant physician and staff of the coronary care unit at the Newcastle General Hospital for their valuable assistance.

-We are, etc.,

\section{Regional Cardiovascular Unit,} Newcastle General Hospital,

1 Sandler, G., and Pistevos, A. C., British Medical M. H. HUSAIN
S. J. JACHUCK

SIR,-The Stoke-on-Trent cannula ${ }^{1}$ was designed specifically for the purpose of carrying out primary operative cholangiography. The cannula is manufactured from flexible polyethylene tubing; because of this flexibility a valid criticism has been the technical difficulty of manipulating it into the cystic duct, particularly if the latter is narrowed. New introducing forceps have now been made to overcome this problem.

The overall length of the forceps is $27.5 \mathrm{~cm}$. They have bow handles and their shanks are slightly curved so that, when held by the operator, his view of the cystic duct will not be obscured. They have a box lock fitting to ensure complete approximation of the jaws, which are $2.5 \mathrm{~cm}$ in length. The jaws are grooved and, when closed, they provide a channel with an internal diameter of $1.3 \mathrm{~mm}$. This receives exactly the Stoke-onTrent cannula, gripping it firmly without undue pressure which would otherwise reduce or obliterate its lumen. The external diameter of the closed jaws is the same as that of the widest part of the expanded distal end of the cannula. The jaws are angled at $80^{\circ}$ to the shaft so that actual insertion into the cystic duct may be facilitated. Finally, the instrument has been given a matt finish to avoid glare and reflection. 